
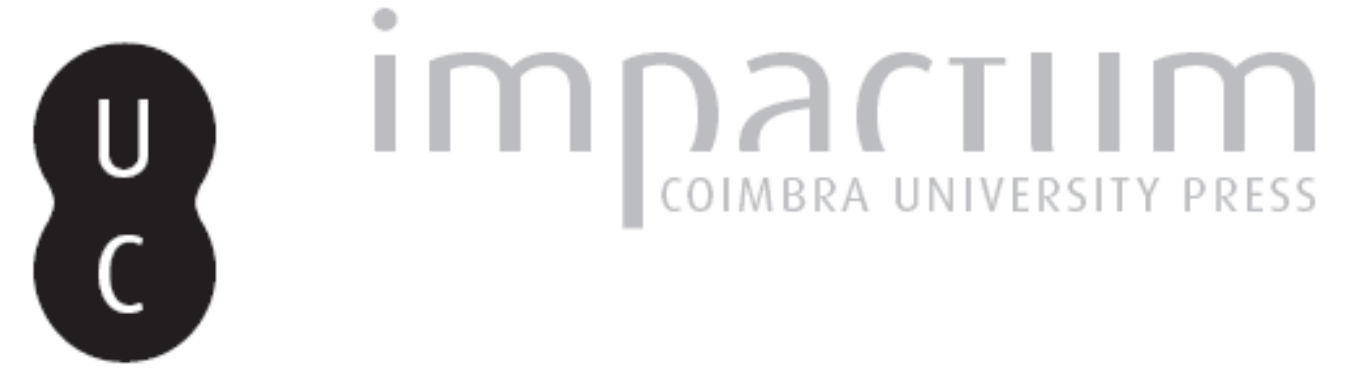

\title{
Radiodifusão pública brasileira: o desafio de conquistar credibilidade e representatividade social
}

Autor(es): $\quad$ Esch, Carlos Eduardo; R. del Bianco, Nélia

Publicado por: Imprensa da Universidade de Coimbra

URL persistente:

URI:http://hdl.handle.net/10316.2/39191

DOI:

DOI:http//dx.doi.org/10.14195/2183-6019_2_9

Accessed : $\quad$ 26-Apr-2023 16:18:25

A navegação consulta e descarregamento dos títulos inseridos nas Bibliotecas Digitais UC Digitalis, UC Pombalina e UC Impactum, pressupõem a aceitação plena e sem reservas dos Termos e Condições de Uso destas Bibliotecas Digitais, disponíveis em https://digitalis.uc.pt/pt-pt/termos.

Conforme exposto nos referidos Termos e Condições de Uso, o descarregamento de títulos de acesso restrito requer uma licença válida de autorização devendo o utilizador aceder ao(s) documento(s) a partir de um endereço de IP da instituição detentora da supramencionada licença.

Ao utilizador é apenas permitido o descarregamento para uso pessoal, pelo que o emprego do(s) título(s) descarregado(s) para outro fim, designadamente comercial, carece de autorização do respetivo autor ou editor da obra.

Na medida em que todas as obras da UC Digitalis se encontram protegidas pelo Código do Direito de Autor e Direitos Conexos e demais legislação aplicável, toda a cópia, parcial ou total, deste documento, nos casos em que é legalmente admitida, deverá conter ou fazer-se acompanhar por este aviso.

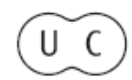


revista de comunicação,

jornalismo e espaço público

2

Periodicidade

Semestral

Imprensa da Universidade de Coimbra Coimbra University Press

\section{mediapolis}

tema

os desafios dos media

de serviço público

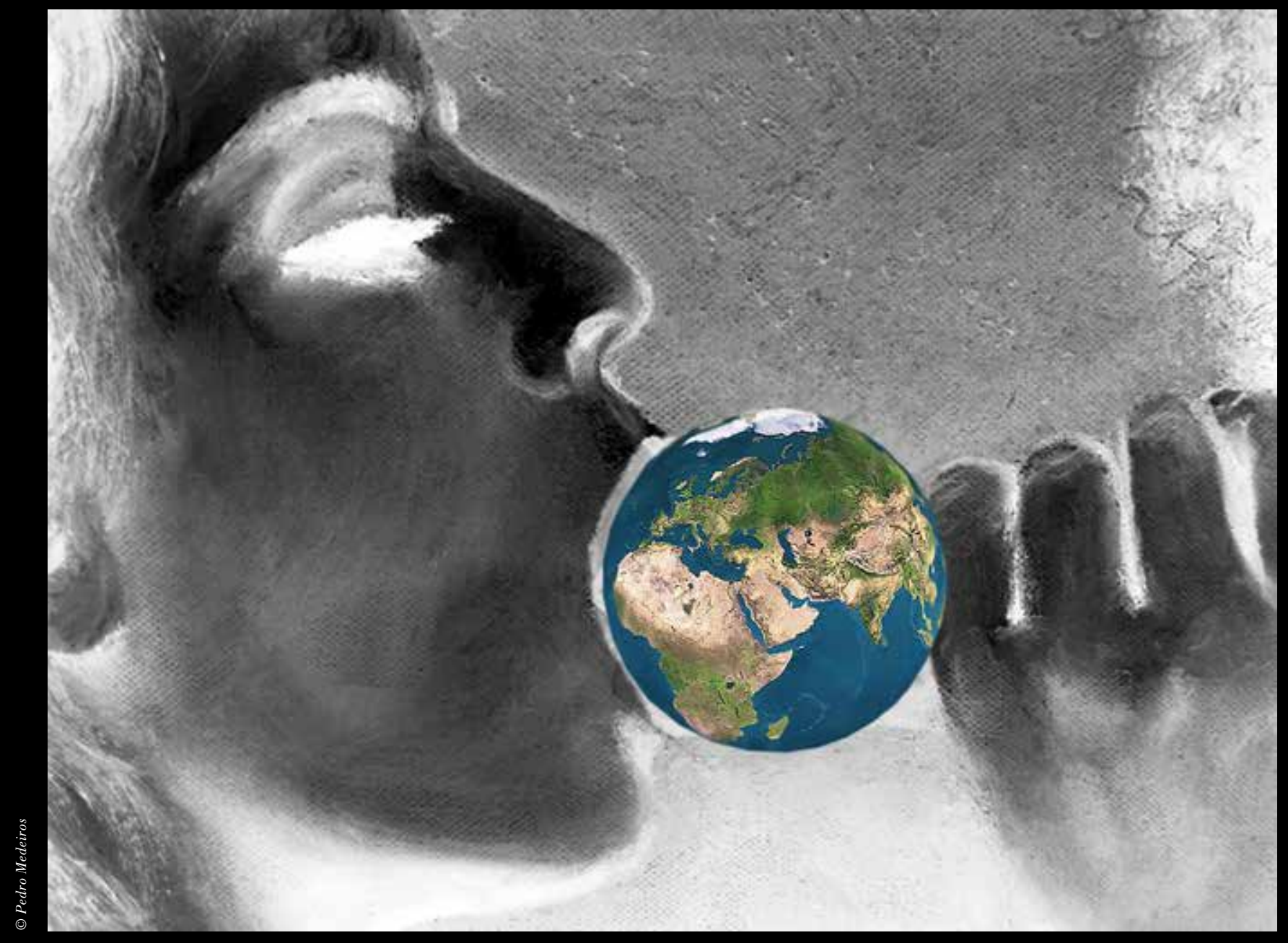




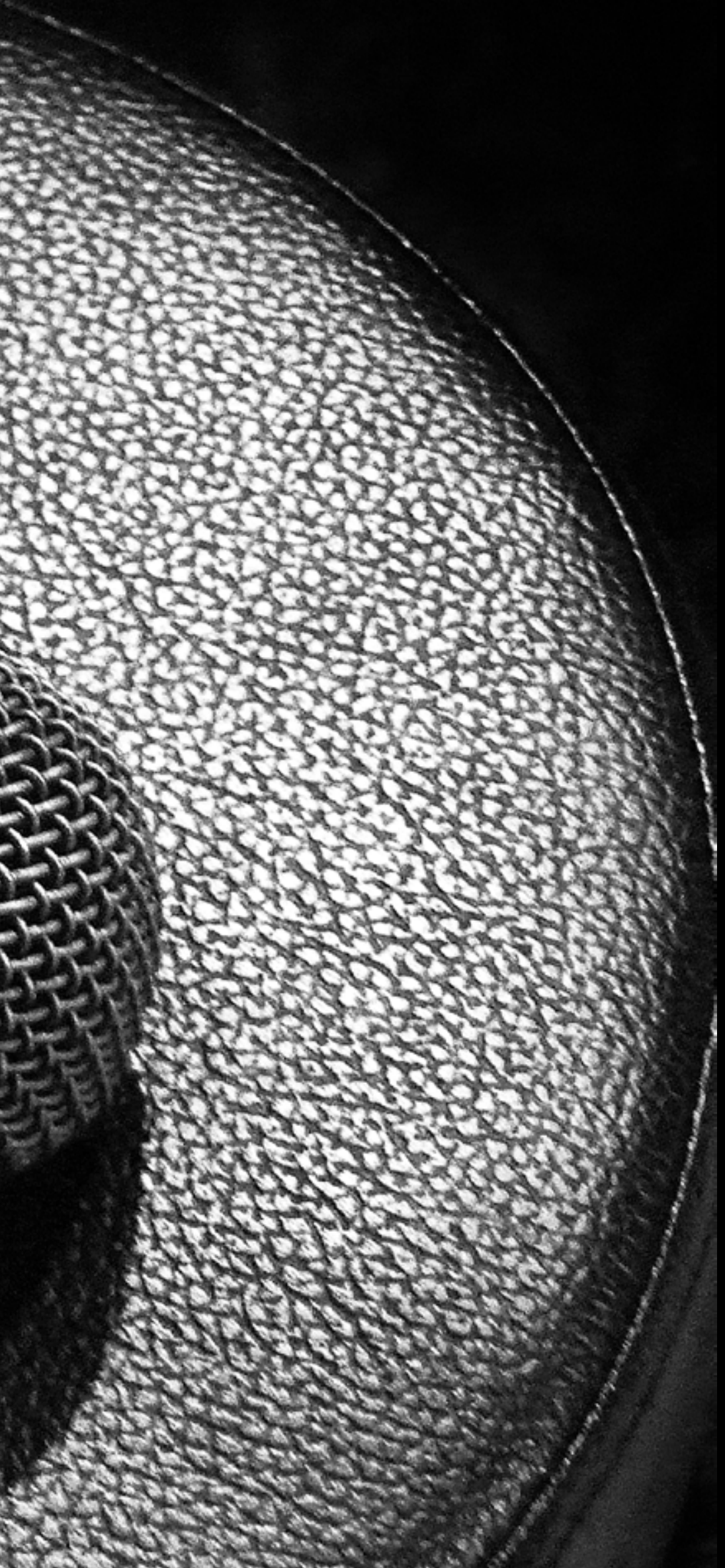




\title{
Carlos Eduardo Esch
}

Universidade de Brasília

caduesch@hotmail.com

\section{Radiodifusão \\ pública brasileira:}

Nélia R. del Bianco

\section{O desafio de conquistar credibilidade e representatividade social}

\author{
Brazilian public service broadcasting: \\ the challenge to build credibility and social representation
}

Resumo:

A estrutura de radiodifusão brasileira é regida constitucionalmente pelo princípio da complementaridade entre os sistemas privado, público e estatal. A comunicação midiática do país foi estruturada, historicamente, com forte predomínio do privado, enquanto as emissoras públicas ficaram numa posição subalterna e marginal quanto a sua representatividade e legitimidade social. Dados de pesquisa realizada no Brasil mostram que, embora mudanças estejam em andamento, as audiências ainda percebem rádios e televisões públicas como meios oficiais, de qualidade inferior e, sobretudo, destituídas de credibilidade. A partir dessa situação, o texto propõe uma reflexão sobre os desafios atuais para a existência das emissoras públicas no contexto midiático e cultural brasileiro em face da urgente necessidade que este segmento tem de reverter a imagem negativa que possui perante o público. $\mathrm{O}$ enfrentamento desse desafio é condição essencial para que rádios e televisões públicas possam, em alguma medida, reinventarem-se perante o ouvinte/telespectador e assim, justificar a necessidade de se promover investimento que garanta a sua existência, permanência e aprimoramento no ambiente audiovisual brasileiro.
Palavras-chave: Radiodifusão, radiodifusão pública, meios públicos, comunicação pública.

\section{Abstract:}

A survey of opinion conducted by the Observatory of Public Broadcasting in Latin America indicates that one of the biggest challenges for Brazilian public broadcasting lies in changing the perception that has been crystallized by the public in relation to such stations. Initial analysis of the data obtained so far shows that the respondents have a negative image in relation to public media. At times, the people manifest themselves in favor of the principles that should delimit the performance of radios and $\mathrm{TV}$, such as diversity, independence and differentiation from commercial media, but, which are not fully followed. At other times they criticize the quality of programming and the political-governmental character of these stations. In this critical scenario, the text presents a discussion on the challenges facing the sector considering the complex historical, cultural, and economic policy circumstances, that have contributed to the maintenance of this "symbolic liability" between media and the audience/ citizens, and which reflects on the possible strategies to face the problem.

Keywords: Broadcasting, public broadcasting, public media, public communication. 


\section{Introdução}

Mudar e mudar rapidamente. Este talvez seja o maior desafio enfrentado atualmente pelos meios públicos de comunicação brasileiros. Uma necessidade de transformação apontada pelos próprios ouvintes e telespectadores que participam da pesquisa intitulada Cidadãos e Meios Públicos ${ }^{1}$, realizada pelo

1 A investigação teve início em julho de 2012 e irá até o final de 2015. O objetivo é avaliar o nível de satisfação do cidadão brasileiro em relação às emissoras de rádio e de TV pertencentes ao campo público. Para isso, foi elaborada uma plataforma virtual de pesquisa, disponível 24 horas, contendo um elenco de questões abertas e fechadas sobre quatro eixos temáticos: consumo midiático dos respondentes; participação/importância dos meios públicos neste consumo; nível de satisfação dos participantes com as programações e programas ofertados; e imagens que a audiência elabora das emissoras de rádio e TV públicas. Participaram da investigação, até o presente, pouco mais de seiscentas pessoas. A meta é alcançar uma amostra composta por duas mil pessoas por meio de uma ampla divulgação em redes sociais e em sites de entidades não governamentais ligadas à defesa da democratização da comunicação e de emissoras públicas de rádio e de TV. Como se trata de uma adesão espontânea à pesquisa, sem estabelecimento de cotas de participantes por faixa etária, escolaridade ou local de moradia, num primeiro momento, os respondentes, na sua maioria $(46.8 \%)$, têm idade entre 20 a 35 anos, $34,6 \%$ vivem na região Sudeste, a mais desenvolvida do país, e 42,9\% no Centro-Oeste. Em relação
Observatório da Radiodifusão Pública da América Latina ${ }^{2}$. As primeiras informações recolhidas e analisadas nos permitem discutir as imagens que a audiência possui das rádios e TV públicas brasileiras. Pode-se afirmar, com base nos dados preliminares, que existe um enorme "passivo simbólico" na relação entre meios públicos e audiência no Brasil. A imagem das rádios e TV públicas sempre esteve atrelada a governos. Embora parte delas tenha feito esforço nos últimos 10 anos para se vincular a princípios de independência, diversidade e oferta diferenciada de conteúdo por meio da renovação de programação, reposicionamento de marca e constituição

à classe social, $37 \%$ deles têm rendimento mensal familiar entre um a três mil dólares. A maioria tem escolaridade alta em relação à média brasileira: ensino superior.

2 Criado em 2011 por pesquisadores brasileiros, o Observatório é vinculado ao Laboratório de Políticas de Comunicação da Universidade de Brasília (UnB) em parceria com o Programa de Pós-Graduação em Comunicação da Universidade do Estado do Rio de Janeiro (UERJ). Trata-se de espaço público online bilingue (português e espanhol), de tipo thinktank, que promove discussão, análises e diagnósticos sobre avanços e impasses na estruturação e manutenção dos sistemas públicos de radiodifusão, por meio de indicadores e ferramentas metodológicas de caráter quantitativo e qualitativo. Endereço: www.observatorioradiodifusao.net.br. de mecanismos de participação social na gestão, a audiência ainda as percebe como veículos de qualidade inferior e destituídos de credibilidade.

\section{Breve contexto da radiodifusão pública}

A radiodifusão pública é percebida na América Latina e, particularmente no Brasil, como sinônimo de mídia governamental. Na maioria dos países do continente o conceito de emissora pública aplicado à radiodifusão tem sido construído pelos operadores dos canais de comunicação sob controle de organismos governamentais pertencentes ao universo da administração pública.

Por essa condição de origem, os sistemas de radiodifusão pública se estruturaram no subcontinente com base em duas tradições: a) sistema público associado aos setores educativo e cultural ${ }^{3}$; e b) sistema público

3 A vertente educativo-cultural teve origem entre as décadas de 1920 e 1930 quando surgiram as primeiras emissoras educativas. As condições limitadas de desenvolvimento na América Latina contribuíam para a manutenção de índices restritos de alfabetização na região, com uma população formada 
vinculado à agenda governamental e estatal ${ }^{4}$. Nestes contextos, as estruturas

por grupos étnicos de origem e conformação cultural bastante diferentes entre si. Pela abrangência e penetração social, o rádio oferecia a possibilidade de alcançar, por meio de escolarização suplementar, públicos não atendidos pelo sistema escolar formal, além de colaborar para vencer as longas distâncias, superando problemas de comunicação em regiões de acesso restrito. Esse vínculo original à ideia de superação do subdesenvolvimento é uma espécie de "mito fundador" do rádio educativo que inspirou / direcionou a maioria dos programas de educação a distância produzidos no Brasil, a partir dos anos 50. A partir da década de 60, o mesmo processo se repete nas primeiras emissoras de TV educativas que operam em instituições estatais, confessionais e universidades.

4 A vertente da radiodifusão pública vinculada à esfera governamental e estatal ocorre a partir da década de 1940 com a criação das chamadas "rádios nacionais", emissoras que surgiram bem estruturadas tecnicamente, capazes de chegar a audiências em todo o território. A programação era constituída por noticiários (em especial aqueles relacionados a atos oficiais do Estado), programas culturais e musicais. Em termos de financiamento foram criadas considerando recursos do orçamento do governo. Ao longo do tempo, essas emissoras converteram-se em porta-vozes de governos, em muitos casos utilizadas como meio para o atingir fins políticos ou promover autoridades governamentais. Seu teor 'oficialista' permaneceu inalterado tanto em governos ditatoriais como em gestões democráticas, com algumas variações nas instâncias de influência por parte do ouvinte/ espectador como, por exemplo, no compromisso com a diversidade da programação, com as formas de acesso e participação da audiência etc. Com o tempo, emissoras educativas e da radiodifusão pública ficaram, tradicionalmente, à margem das políticas de investimento e custeio dos governos que, no contexto institucional continental da América do Sul, deveriam sustentá-las. Isso ocorreu ao longo do tempo e continua acontecendo, por falta de capacidade financeira, pela falta de visão estratégica, de projetos e de planejamento governamental ou, em casos mais graves, pela adoção de políticas de favores e privilégios oferecidos à mídia privada baseada nos grandes conglomerados empresariais de comunicação ${ }^{5}$.

governamentais amargaram a perda gradual de audiência e de credibilidade. Nas décadas de 1980 e 1990 tiveram sua sustentabilidade ameaçada pela crise financeira mundial que impulsionou mudanças estruturais na definição do tamanho do Estado.

5 Em uma análise da situação dos meios públicos no continente, o pesquisador chileno Valério Fuenzalida (Fuenzalida, 1998) aponta três razões estruturais para a crise que atingiu o segmento com maior intensidade na década de 90: a) a má administração industrial/empresarial em consequência de uma direção executiva sujeita à interferência política que gera descontinuidade de metas, muitos casos de corrupção e de irresponsabilidades impunes; b) a falta de sustentabilidade econômica, agravada pela estratégia de subsistir ignorando os interesses da audiência e sem estabelecer mecanismos para diversificar o financiamento; c) a programação pouco atraente, que não
Outro aspecto a ser considerado é que a radiodifusão financiada pelo Estado surge como "lugar privado" em contextos onde a estrutura midiática passa a trabalhar mais em beneficio do grupo político que controla transitoriamente o governo e em detrimento dos reais interesses da população ${ }^{6}$. É preciso considerar também que no início do século XXI, com a ascensão ou reafirmação no poder de governos de partidos de esquerda (a exemplo de Brasil, Bolívia, Paraguai e Equador), comprometidos historicamente com

seduz o grande público e a mantém restrita à audiência marginal. Segundo o pesquisador, no contexto da década de 1990 , em que se desconfiava da capacidade administrativa do Estado, não havia respaldo político para propostas de investimento de dinheiro público em canais operados de modo ineficiente e com audiência insatisfatória.

6 Isso ocorre nas emissoras: a) pela ausência de uma cultura de práticas públicas sustentada por procedimentos e ações efetivamente democráticas e de consolidação dos valores públicos; b) pela inexistência de um conjunto de regras profissionais (impessoais) que proteja as estruturas públicas de comunicação de influências e desmandos políticos de momento; c) pela falta de interesse em promover uma legislação que pudesse garantir independência econômica e regras previsíveis e estáveis de repasses financeiros incluídos nos orçamentos governamentais e d) pela necessidade de profissionalização do corpo técnico, gerencial, operacional das estações públicas. 
grupos de defesa da democratização dos meios de comunicação, teve início o processo de reorganização dos canais educativos, culturais ou estatais, aproximando-os de preceitos que os caracterizam como serviço público. Apesar das resistências e conflitos verificados em cada contexto nacional, é possível afirmar que existem tentativas consistentes de implantar mudanças algumas tímidas e outras audazes - nos marcos normativos de vários países e na reorganização da gestão de emissoras. A forma como esse processo de transformação está ocorrendo dá pistas sobre o grau de maturidade de cada país para estabelecer consenso social em torno da proposta de oferecer à população um serviço público de comunicação independente e democrático.

\section{Contexto recente brasileiro}

A radiodifusão pública brasileira parece viver na atualidade um aparente paradoxo. De um lado, têm-se intensificado as discussões sobre o papel público que rádios e TV, financiados por recursos governamentais, devem ter na sociedade brasileira e sobre os limites da influência que os governos devem exercer sobre estes meios. De outro, pela existência de um contexto social marcado pelo desconhecimento, rejeição e preconceito de grande parte dos cidadãos, sobre o real papel desempenhado por meios governamentais e ou públicos ao longo da história e até mesmo sobre as possibilidades imaginadas para o futuro.

Com a chegada a presidência da república de Luiz Inácio Lula da Silva (2003-2010), o governo tentou promover juntamente com entidades da sociedade civil ações cujo objetivo fora redirecionar as discussões sobre o papel e o funcionamento dos meios de comunicação brasileiros. Especificamente no âmbito da radiodifusão pública, a criação da Empresa Brasil de Comunicação - $\mathrm{EBC}^{7}$ em

7 Criada pelo governo federal em 25 de outubro de 2007, quando da publicação no Diário Oficial da União, do decreto 6.246 de 24 de outubro de 2007 e convertida em lei no 11.652 de 7.04.2008. Trata-se de uma empresa pública vinculada à Secretaria de Comunicação Social da Presidência da República. Congrega uma agência nacional de notícias, três canais de TV, sendo que um deles atua em rede nacional, e mais sete emissoras de rádio. A EBC Serviços é o braço estatal da empresa responsável pela operação e gestão de todas as atividades
2007 pode ser considerada um marco nesse processo. Com a aprovação da lei de criação da empresa, o governo definiu objetivos e princípios que devem pautar a conduta de serviços de radiodifusão explorados pelo poder executivo de âmbito federal ${ }^{8}$.

de interesse da Secretaria de Comunicação Social do Governo Federal - Secom, que estavam sob a responsabilidade da extinta Radiobrás - empresa estatal que deu origem a EBC. Entre os mais de 20 serviços prestados à Secom, nas áreas de televisão, rádio, clipping e publicidade, estão a operação da NBR - a TV do Governo Federal; a produção e a veiculação de A Voz Brasil - bloco do Poder Executivo; a produção e a distribuição do Café com o Presidente; a cobertura e a transmissão dos atos da Presidência da República; a intermediação de toda a Publicidade Legal do Governo Federal; a edição da Mídia Impressa, além de diversos serviços de clipping.

8 Entre os objetivos estão: oferecer mecanismos para debate público sobre temas de relevância nacional e internacional; desenvolver a consciência crítica do cidadão mediante programação educativa, artística, cultural, informativa, científica; apoiar processos de inclusão social e de socialização da produção de conhecimento garantindo espaços para exibir produções regionais e independentes; buscar excelência em conteúdos e linguagens e desenvolver formatos criativos e inovadores, constituindo-se em centro de inovação e formação de talentos; direcionar sua produção e programação pelas finalidades educativas, artísticas, culturais, informativas, científicas e promotoras da cidadania, sem com isso retirar seu caráter competitivo 


\section{A radiodifusão}

financiada pelo

Estado, no Brasil,

surge como

"lugar privado",

em benefício do

grupo político

que controla

transitoriamente

o governo
O modelo institucional da EBC contempla mecanismos típicos do serviço público. A gestão da empresa se concentra em torno de três conselhos - administrativo, financeiro e curador - e uma diretoria executiva. A ideia é que os conselhos se regulem entre si e regulem o funcionamento da empresa e, sobretudo, em relação ao cumprimento do seu compromisso social na produção e transmissão de conteúdos de qualidade e interesse público. O Conselho Curador é o instrumento de participação da sociedade na gestão da empresa ${ }^{9}$. Entre as suas atribuições estão a aprovação do plano de trabalho anual da empresa, ratificar e acompanhar a aplicação da linha editorial e observar a veiculação da programação, fiscalizando e fazendo recomendações de acolhimento obrigatório pela diretoria-executiva da organização. Apesar de lutar pela

na busca do interesse do maior número de ouvintes ou telespectadores.

9 O Conselho Curador da EBC é composto por 22 membros: 15 representantes da sociedade civil, quatro do Governo Federal (ministros da Educação, Cultura, Ciência e Tecnologia e Secretaria de Comunicação Social da Presidência da República), um da Câmara dos Deputados, um do Senado Federal e um funcionário da Empresa. autonomia editorial frente ao governo, a estreita relação com o Executivo fica evidente ao ter o diretor-presidente e diretor-geral da empresa indicados diretamente pela presidência da República. Além disso os representantes da sociedade no Conselho Curador precisam passar pelo aval do Presidente da República. O governo ocupa também a maioria das cadeiras de dois dos três conselhos ${ }^{10}$.

É certo que a EBC é um exemplo importante do que ocorre na radiodifusão pública no Brasil, mas ela significa apenas uma parcela pequena do setor. No país estão em

10 Ao mesmo tempo, sua sustentabilidade por meio de fundos públicos enfrenta resistência. A lei de criação da EBC previu que seu financiamento seja constituído, em parte, pela Contribuição para o Fomento da Radiocomunicação Pública com recursos oriundos do Fundo de Fiscalização das Telecomunicações. Mesmo sem representar uma nova taxação para as operadoras, as empresas de telefonia brasileiras moveram uma Ação Direta de Inconstitucionalidade para questionar a utilização de recursos do Fundo destinados para as telecomunicações na radiodifusão pública. A ação continua em trâmite na Justiça aguardando decisão final. Enquanto isso, a EBC segue dependente dos recursos do Tesouro Nacional, impedida de anunciar bens e serviços de empresas privadas, apesar de fazer propaganda de órgãos públicos e receber apoio cultural para algumas produções. 
funcionamento cerca de 200 rádios e 90 canais de $\mathrm{TV}^{11}$ vinculados a instâncias de poder político como governos estaduais e municipais, bem como, a universidades públicas. São canais definidos pela legislação brasileira como exclusivamente de finalidade educativa, não tendo caráter comercial e nem fins lucrativos.

De acordo análise do Observatório da Radiodifusão Pública sobre o modelo de funcionamento e gestão que abrangeu 30 emissoras de TV e 70 de rádio do país, boa parte delas funciona muito mais como instituições governamentais do que propriamente entidades que possuem vínculos estreitos com a população, que dela participam e na qual percebem alguns de seus interesses refletidos no conteúdo das programações que oferecem (Bianco, Esch \& Moreira, 2012). Além da EBC foram identificadas no país somente mais quatro empresas públicas e fundações que instituíram conselhos com representantes da sociedade civil atuando no sentido de supervisionar a gestão de

11 Dados do Ministério das Comunicações. Disponível em http://www.mc.gov.br/acoes-e-programas/radiodifusao/dados-gerais suas emissoras. O modo de funcionamento desses conselhos nem sempre segue parâmetros de transparência, tais cromo critérios claros para escolha de representantes da sociedade ou divulgação de atas de reunião.

Observou-se, ainda, que, embora a lei de criação da EBC tenha estabelecido princípios de atuação pautada pelo interesse público como autonomia, independência, diversidade de conteúdo e participação social, emissoras subordinadas a instituições federais, como as universidades públicas, por exemplo, não alteraram substancialmente seu modelo de organização e gestão.

$\mathrm{Na}$ análise sobre o funcionamento e as rotinas das instituições fica claramente perceptível que existe um "déficit" entre o marco regulatório de algumas emissoras e a cultura pública de funcionamento interno praticada no cotidiano delas. Muitas ainda guardam uma forte relação com o governo, responsável direto pelo repasse de verbas para sua manutenção. Condição de dependência que favorece o estabelecimento de uma situação indesejável de subordinação política e editorial.

\section{O modelo}

institucional da

EBC contempla

mecanismos

típicos do serviço

público. A gestão

da empresa se

concentra em torno

de três conselhos

- administrativo,

financeiro e

curador - e uma

diretoria executiva 


\section{Para compreender o que pensa a audiência}

Para compreender os significados da defasagem de imagem entre os meios públicos e a audiência, partimos de uma perspectiva de análise que contempla as condições de origem e funcionamento de rádios e TV públicas, suas ações, programações, produções e a sua própria trajetória histórica em um contexto social construído a partir da interação entre seus membros e instituições. Uma interação que ocorre em distintos níveis e de forma diferenciada, mas que é, fundamentalmente, a característica que marca a vida em sociedade e a convivência em grupo. A relação entre os meios públicos e a audiência está imersa no campo das interações que ocorrem na vida cotidiana. É parte de um fenômeno maior que caracteriza as sociedades contemporâneas a partir da forte e progressiva presença da comunicação massiva eletrônica no acontecer social contemporâneo.

$\mathrm{O}$ conceito fundamental do qual parte nossa análise é o da interação. Etimologicamente, a palavra interação expressa, primordialmente, a noção de desenvolvimento de uma ação mútua, ou seja, pressupõe reciprocidade entre todos aqueles que dela participam. Em uma relação não basta apenas perceber o outro para que se estabeleça a interação. Deve-se produzir uma modificação na percepção do sujeito que aprecia, a partir da resposta que o sujeito observado oferece diante da sua ação. Da mesma maneira, o fato de que o sujeito percebido sinta-se assim, observado, pode provocar-lhe desejos de modificar a sua aparência, modificar suas atitudes, sua forma de falar, sua conduta ou qualquer outro elemento que sirva de referência para a elaboração de juízos formados no sujeito que percebe, transformando a sua percepção. Em síntese, esse processo contínuo de observação e resposta está na base da relação que une, inclusive, os meios de comunicação, sejam eles quais forem, e suas audiências, como possíveis segmentos de consumidores.

Percebe-se, assim, que a interação é, essencialmente, uma relação dialética pois, a natureza retroalimentadora da ação entre as partes envolvidas nela, permite que a interação seja o momento no qual as relações sociais atualizam e se reproduzem continuamente. Pode ser também um espaço para a intervenção e inovação e onde, em cada momento, se fundam e refundam os vínculos sociais (Mead, 1982). Laços que conformam a sociedade a partir da atuação dos grupos sociais formados por uma diversidade de consciências individuais que agem e reagem umas sobre outras desde a comunicação estabelecida.

É pela existência dessas ações e suas consequentes reações, ou seja, pelo conjunto de interações estabelecidas que reconhecemos uma determinada sociedade (Mauss, 1969). Portanto, a interação pode ser vista como um "fenômeno social total" no sentido que entendia Mauss, ou seja, um fenômeno implicado na totalidade da sociedade e suas distintas instituições nas quais interatuam, simultaneamente, as dimensões psicológicas, culturais e sociais.

Essa perspectiva, desenvolvida pelo interacionismo simbólico, parte de três pressupostos. O primeiro considera que o ser humano adquire uma postura diante das coisas com as quais se depara no mundo, de acordo com o que estas significam para ele. $\mathrm{O}$ segundo é que os significados que 
tais coisas adquirem, são fruto da interação social que cada um de nós mantém com os demais que compartem o mesmo espaço social. E, finalmente, o terceiro pressuposto diz que os significados surgidos dessas interações se manipulam e são alterados por meio de um processo de interpretação realizado pela pessoa, à medida que se confronta com o universo de coisas compostas a partir de suas vivencias como ser (Blumer, 1982; Perrota, 1988; Baert, 2001).

A visão interacionista sustenta que o significado não emana, enquanto proprietário de uma natureza própria, do objeto e nem "brota" na percepção do ser humano a partir de processos de índole merarmente psicológica, mas é o resultado de um processo de interação entre os indivíduos. Nesse processo, o significado que uma coisa encerra para uma pessoa é o resultado das distintas formas como outras pessoas atuam diante dela em relação a essa coisa. Os atos dos demais produzem o efeito de definir-lhe a coisa a essa pessoa (Ritzer, 2002). Ou seja, para o interacionismo simbólico o significado se constitui, sobretudo, socialmente por meio de um conjunto de ações definitórias que são desenvolvidas pelos indivíduos a medida que interagem (Mead, 1982).

Diante dessa perspectiva, para esclarecer as circunstâncias ao redor do estabelecimento de imagens pelos cidadãos brasileiros sobre meios de comunicação públicos, é necessário ter em mente, em primeiro lugar, a natureza processual da ação comunicativa cotidiana das emissoras de rádio e televisão. Ao falarmos de imagens, estamos nos referindo aos sentidos que emergem a partir de uma atuação diária, continuada e histórica, na qual os meios se confrontam ao longo do tempo com uma série de situações e fatos que ocorrem no mundo e que invadem - ou não - seus programas e programações sob a forma de notícias, opiniões e, até mesmo, manifestações da própria audiência.

Dessa forma, os meios elaboram uma série de significados sobre todos esses acontecimentos, os quais alimentam diariamente os discursos midiáticos transmitidos aos ouvintes e aos espectadores. Ao longo desse processo, também se compõem imagens e simbolismos vinculados aos meios e constituídos a partir do que pensam, acreditam, criticam e elogiam as audiências destes veículos. A formação destas imagens e a carga de sentido que contêm podem ser compreendidas a partir de dois momentos consequentes.

$\mathrm{O}$ primeiro tem relação com a forma como os meios atuam e, consequentemente, com os potenciais papéis que passam a desempenhar perante o público. O significado que cada meio passa a ter diante de seu público é o resultado direto de um dinâmico processo de avaliação que a audiência elabora do que o meio faz, oferece, defende ou omite em sua programação e da forma como o faz. $\mathrm{O}$ segundo pertence exclusivamente à audiência e surge desse processo de apreciação no qual cada um de seus membros, a partir de suas necessidades e valorações, atribui os significados que os meios e seus programas assumem no contexto das experiências individuais.

Esse fenômeno de constituição de representações simbólicas corrobora a ideia de que a característica fundamental da humanidade e dos processos que conformam a vida social é a utilização de uma grande variedade de símbolos com distintos graus de 
complexidade (Saperas, 1998). A comunicação realizada através dos veículos, inclusive os públicos, não está à margem disso. Ao contrário, se apresenta como uma ação de sentidos e se caracteriza como um "instante" a mais do processo social, no qual se estabelecem, continuadamente, uma série de relações recíprocas entre indivíduos e instituições, inclusive as midiáticas. Nesse contexto, meios e audiência, interagem com fatos, pessoas, ideias e situações que acabam pautando, de alguma forma, as posturas, posições e comportamentos que ambos poderão adotar. Disto se infere que, em razão das diferenças encontradas nos contextos e nos processos individuais e coletivos de interação social, pode se produzir uma maior ou menor aceitação dos próprios meios e do que eles apresentam aos seus públicos.

Por isso é certo que o "tom" das ações, programações e dos produtos que produzem acabam influenciando favoravelmente, ou não, no surgimento de sentimentos de respeito, admiração, valoração e aprovação por parte do público em relação a determinadas emissoras de rádio ou de televisão. No final das contas, recordemos que os programas são produzidos e emitidos em ambientes sociais distintos com variações significativas de necessidades e desejos por parte de um público que é segmentado por diferenças múltiplas.

Assim, no meio dessa complexa dinâmica interativa estabelecida entre variados atores da cena social - aqui representados por ouvintes/espectadores e meios públicos - que se "encontram" nos espaços discursivos elaborados pelas suas programações, é que se configuram e adquirem sentido as ações midiáticas e se estabelecem suas repercussões reais e/ou simbólicas. E foi para revelar alguns dos significados que conformam a imagem dos meios públicos é que nos propusemos a ouvir o público brasileiro, suas ideias e conceitos sobre esse universo midiático em particular.

\section{Nível de satisfação \\ da audiência com \\ os meios públicos}

A relação entre meios públicos e audiência abriga uma interação "primordial" que é estabelecida no âmbito do consumo de mídia. Entre os participantes da pesquisa "Cidadãos e Meios Públicos", observa-se que a Internet e o celular tornaram-se o novo suporte para se consumir a música, a informação e o entretenimento anteriormente oferecido pelas mídias tradicionais. Enquanto 97\% utilizam diariamente a internet e $93 \%$ o celular, cai quase pela metade o hábito de ver TV aberta (57\%), TV por assinatura (50\%) e rádio (46\%). Trata-se de um público que consome Internet em qualquer lugar, em casa, no trabalho, na escola, em lugares públicos. No rádio, seu interesse é ouvir música e notícias. Enquanto na TV aberta, a predileção é por noticiários, na TV por assinatura o consumo maior é de filmes, documentários e séries internacionais ${ }^{12}$.

Em relação ao consumo de meios públicos, há mudanças significativas se comparado com as respostas oferecidas sobre a mídia comercial. Quando

12 Pode-se afirmar que o nível de importância para as suas vidas atribuído pelos participantes da pesquisa aos meios de comunicação, se encontra entre 3 e 5 em uma escala valorativa na qual 1 é nenhuma importância e 5 muito importante. Nessa escala, a Internet é a única que está no nível "muita importância" no cotidiano (87\%), seguido pelo celular $(66 \%)$. 
se perguntou qual a primeira ideia que surge na mente quando se fala em rádios e TV públicas, dois terços fizeram comentários negativos por acreditarem que estes meios estão historicamente vinculados aos governos:

"Lugar de politicagem do governo..."

"Lugar de propaganda descarada dos governos..."

"Programação direcionada para o governante do momento"

"São governistas ao extremo, menos públicas..."

"São voltados para noticiar aquilo que interessa ao governo..."

"Tudo fachada. Deveriam ser confiáveis e mais isentas que as privadas, mas não é a nossa realidade..."

O que mais chama atenção é que essa percepção é formada a partir de um baixo nível de consumo dos próprios meios públicos. Enquanto a maioria sempre vê TV (54\%) e ouve rádios comerciais (29\%), 41\% declaram assistir a TV pública somente às vezes e $27 \%$ dizem que raramente ouvem rádio pública. A baixa frequência desse consumo é significativa: $52 \%$ veem TV e $41 \%$ ouvem rádio públicas de 3 a 1 vez por semana. No entanto, é preciso destacar que quase $30 \%$ disseram nunca ouvir rádio e $18 \%$ nunca assistem a TV pública. Embora esse grupo não seja consumidor, fez comentários negativos sobre os meios públicos. É provável que essa opinião tenha sido formada a partir da imagem socialmente construída e disseminada, ao longo do tempo, e que perfilam meios públicos como sinônimo de esfera de ação governamental. Nesse sentido, a dimensão governamental pode ser entendida como algo distinto do que deveria ser o papel dessas emissoras, ao atuarem, idealmente falando, a serviço do interesse público.

A partir dessa perspectiva, os participantes da pesquisa, em sua maioria, entendem que os meios públicos não os representam. E defendem ideias a respeito de como deveriam atuar:

"Deveriam ser instrumentos originais de comunicação que ajam conforme interesse público, coisa difícil no nosso país..."

"Deveriam ser espaços onde a voz comunitária tem espaço. $\mathrm{Ou}$ melhor, onde a mídia se volta para a produção de conteúdo que enriqueça a sociedade..."

"Penso que deveriam ser meios de comunicação que veiculam ações e produtos destinados ao interesse público, como educacionais, culturais e de cidadania... ainda falta no Brasil"

A partir da pesquisa foi possível também interpretar uma terceira via de críticas aos meios públicos, relacionada agora com a linguagem adotada por programas que fazem parte das grades de programação. De modo geral, $41 \%$ dos que ouvem rádio e quase metade (48\%) dos que veem TV pública se dizem parcialmente satisfeitos.

Aqueles que consomem, com alguma frequência TV públicas estão parcialmente satisfeitos com noticiários (48\%), programas de entrevistas (41\%), filmes (36\%) e documentários (35\%). Em relação ao rádio, o público se diz satisfeito (42\%) apenas com a programação musical. Em relação aos programas jornalísticos, a maioria está parcialmente satisfeita com noticiários $(38,4 \%)$ e programas 
Gráfico 1

Nível de satisfação com a qualidade dos

conteúdos educativos e culturais oferecidos

pelas programações das emissoras públicas.

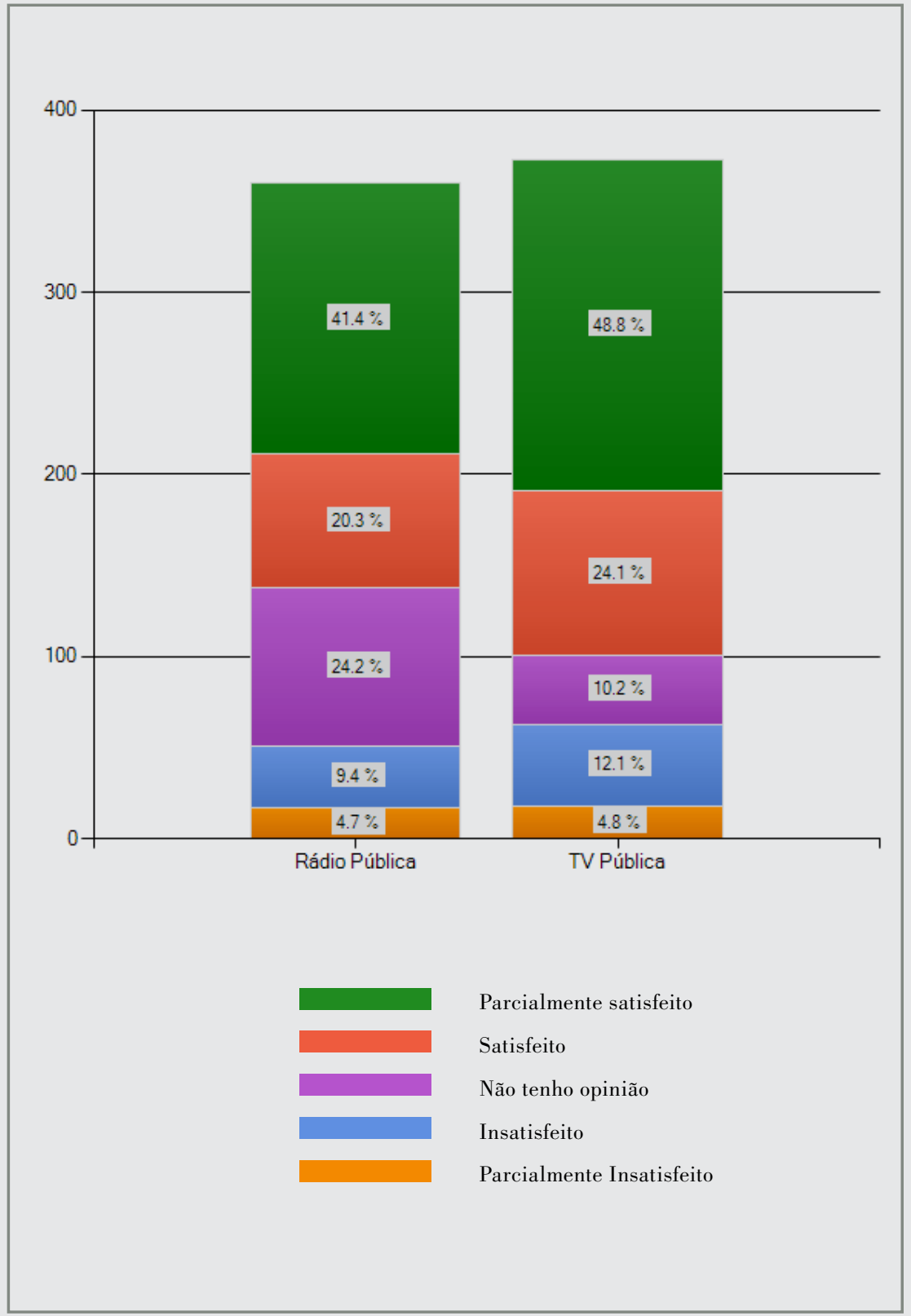


de entrevistas $(38,1 \%)$. A satisfação parcial pode ser explicada pela percepção de que a programação não é atraente do ponto de vista estético e de linguagem:

\footnotetext{
"Uma coisa chata e maçante..."

"Má qualidade da programação..."

"Programas aborrecidos e ente-

diantes..."

" Emissoras com programação ruim e chata de se ver e ouvir..."

"As rádios públicas não se mostram convidativas aos ouvintes na forma como são feitas e na forma como são transmitidas, tornando-se cansativas. Já as televisões públicas atendem apenas a interesses específicos dos espectadores e, por isso, acabam sendo acessadas somente, e apenas, quando há algum interesse muito pontual..."
}

O jornalismo de parte das emissoras públicas foi criticado pela audiência por não oferecer, de forma substancial e significativa, noticiários que poderiam ser uma alternativa à produção da mídia comercial. Quando perguntados se o jornalismo é de boa qualidade, $47 \%$ disseram concordar parcialmente. A mesma avaliação foi maioria para afirmações como "aborda temas de interesse da população" (44\%), "aborda temas de interesse do governo" (34\%), "oferece diversas perspectivas da notícia" (36\%), "é imparcial" (26\%). A falta de independência editorial é apontada como um problema para metade dos participantes que disseram assistir a TV pública:

"O jornalismo e os programas de entrevista da TV Cultura tem tradição em ser de ótima qualidade, mas nos últimos anos tem se mostrado tendencioso em favor do governo estadual de São Paulo, com agravamento desde meados de 2012."

"A TV Brasil inda mostra muita incidência de cobertura do governo Dilma."

"Ainda conserva o padrão do jornalismo praticado pelas emissoras comerciais privadas. Falta ousadia e abertura à experimentação. Deve incentivar mais as coberturas nacionais com destaque para as noticiais de todas as regiões do Brasil."
Embora façam criticas baseadas na ideia de que as emissoras deveriam seguir princípios de diversidade, independência e pluralidade de visões, a audiência chega a reconhecer méritos de parte da programação. Por exemplo, a maioria observa que nem a TV nem a rádio pública exibem programas sensacionalistas (58\%), que o conteúdo da programação é variado (37\%) e que, na construção das notícias, ainda conseguem fazer uma abordagem um pouco mais aprofundada em relação às emissoras comerciais $(30 \%)$.

\section{Em defesa de meios públicos em sociedades democráticas}

A radiodifusão no Brasil se estruturou em torno das emissoras comerciais graças a uma relação contígua que se estabeleceu entre as empresas de comunicação e os agentes políticos. Essa proximidade permitiu, ao longo do tempo, um sistema de concessões públicas estabelecido e operado a partir de interesses e conveniências político-partidárias, seja na obtenção de incentivos e subsídios fiscais, participação privilegiada na distribuição 
da verba publicitária governamental, obtenção de vantagens pelo desenvolvimento direcionado de infraestruturas de telecomunicações e pelo estabelecimento de atos regulatórios que garantiram o livre fluxo de capitais. $\mathrm{O}$ modelo simbiótico entre comunicação e política favoreceu a uma forte concentração de poder econômico, político e simbólico nas mãos de entidades privadas.

Em contraste a hegemonia dos meios privados, os veículos públicos ficaram em segundo plano, condição agravada pelo atrelamento de emissoras a governos, pela falta de investimentos na infraestrutura e para a produção de conteúdo, dificuldades estruturais e burocráticas para renovar quadro de profissionais entre outras. Embora esse ambiente de marginalização tenha colaborado para o estabelecimento de uma percepção pública negativa, os participantes da pesquisa entendem (68\%) que rádios e TV públicas são importantes para a democracia e, por isso, devem ter sua existência garantida e apoiada. Quase metade $(45 \%)$ reconhece que há diferenças significativas de qualidade entre as programações de TV e rádios públicas e as congêneres comerciais. Acreditam que há potencial desse segmento em oferecer diversidade de conteúdos sobre a cultura brasileira (41\%), de apresentar programas que permitam conhecer mais o Brasil e sua própria cidade (43\%) e, por fim, pensam que as emissoras públicas também são capazes de entreter e educar $(32 \%)$.

O reconhecimento desse potencial, no entanto, não leva a audiência a concordar com a possibilidade de implantar modelos tradicionais de sustentação financeira de meios públicos através da adoção de taxas específicas pagas pelo cidadão. Para $43 \%$ dos respondentes é inaceitável pagar uma taxa específica para a manutenção dessas emissoras. Também recusam a ideia de mantê-las exclusivamente com recursos publicitários (55\%). A saída seria estabelecer um financiamento misto. A maioria (37\%) está totalmente de acordo com a ideia de que emissoras públicas deveriam ser mantidas com recursos públicos e publicitários. Há razões históricas para essa postura evidenciada em comentários dos participantes da pesquisa:
Não há problema em ter recursos publicitários desde que os comerciais veiculados não sejam de produtos prejudiciais à saúde e/ ou que causem danos evitáveis ao meio-ambiente e, principalmente, desde que isso não interfira na imparcialidade dos programas veiculados. Pagar uma taxa, a curto prazo, parece impraticável no Brasil. Contudo, num momento futuro, pode ser viável, desde que potencializadas as produções desses veículos e a participação do público na definição e análise do conteúdo produzido.

"Embora a história, mostre a dificuldade de se manter emissoras públicas apenas com dinheiro público, por outro lado, acho desinteressante ter que brigar por audiência e se "nivelar por baixo" para conseguir patrocínio. Com tantos impostos que pagamos, com certeza, se tudo funcionasse direito, se todos os funcionários fossem concursados (para não haver cabide de emprego a cada mudança de mandato) não faltaria dinheiro. Nem imagino para 
nada porque já pagamos muitos impostos e um dos retornos deveria ser uma comunicação pública de qualidade, sem politicagens".

\section{Passivo simbólico}

Esses primeiros dados interpretados indicam que o grande desafio para o segmento da radiodifusão pública brasileira será superar o que chamamos de "passivo simbólico" perante a audiência nacional. A ideia do passivo simbólico se apoia na concepção de que existe um representativo déficit de imagem da mídia pública perante a audiência, ou seja, ao longo da história parece haver se constituído um "saldo simbólico negativo", relacionado ao processo de constituição das imagens estabelecidas pelos meios públicos perante o cidadão brasileiro. Essa defasagem se materializa por meio das dúvidas que os cidadãos apresentam quanto: a) a qualidade do trabalho que as emissoras realizam frente à relativa independência perante a estrutura governamental que as financiam e subordinam administrativamente; b)

\section{A vinculação dos meios públicos}

com a percepção

negativa de

atrelamento a

governos produziu

um significado

social que criou

distanciamento

entre audiência

e meios a real natureza das propostas de suas programações no tocante à qualidade do conteúdo oferecido e a atratividade dos programas. Esse desencontro de perspectivas gera um contexto paradoxal sintetizado pela contraposição entre a imagem que mídia pública tem de si e a que o público faz dela. A predominância da desconexão acaba fazendo com que parte significativa da população situe esses meios em uma espécie de "gueto simbólico" que qualifica e define o valor, importância e representatividade que ocupam no cenário midiático e cultural brasileiro e que os isola e os diferencia, qualitativamente, dos meios comerciais.

Sob a perspectiva do interacionismo simbólico, o sujeito é concebido como um ser que age no presente, sendo influenciado não somente pelo que aconteceu no passado, mas também pelo que acontece no tempo da interação. A ação do sujeito está relacionada com o significado que ele tem do mundo. Historicamente foram construídos no Brasil significados negativos dos meios públicos referendados por práticas que distanciavam suas atuações do que se espera de um serviço de 
interesse público, a exemplo da vinculação estreita com estruturas de governo, acabando, assim, por minar sua autonomia e independência.

Ao lado disso, agrega-se a percepção dos brasileiros que desvincula o governamental/estatal com a dimensão pública. Essa visão tem sido alimentada por formas de exclusão social vivenciadas cotidianamente pelo cidadão (falta de moradia, de saúde, de educação entre muitas outras), além da incapacidade e da inoperância da administração pública em oferecer serviços básicos de modo satisfatório. Outro fenômeno que fragiliza a noção de Estado como promotor do bem-público é a prática do patrimonialismo, que ocorre quando o governante trata a administração política como assunto pessoal, ao mesmo tempo em que explora a posse do poder político como se fora predicado de sua propriedade privada. A gestão patrimonial consiste em administrar e proferir sentenças caso a caso, combinando o exercício discricionário da autoridade pessoal com a consideração imbuída na tradição ou de acordo com os direitos individuais estabelecidos. Pautado pelo clientelismo, não se estabelece uma administração profissional, independente, e nem o Estado realiza, em sua completude, os desígnios de ordem coletiva aos quais se presta a proteger (Bendix, 1986; Buarque de Holanda, 1995).

Conclui-se que a vinculação dos meios públicos com a percepção negativa de atrelamento a governos produziu um significado social que criou distanciamento entre audiência e meios. E mesmo quando parte das emissoras já está promovendo mudanças na programação e se pautando, de modo mais claro, por princípios de diversidade e pluralidade, ainda não houve tempo suficiente para que novas imagens pudessem ser constituídas e introjetadas pelos cidadãos. Uma das barreiras para que o cidadão perceba e compreenda simbolicamente as mudanças que estão em curso no setor está no que definimos como "passivo simbólico", uma espécie de "lastro histórico de avaliações negativas" que associa no imaginário coletivo os meios públicos à falta de qualidade e de autonomia com relação a instâncias de poder governamental.
A existência dessa perspectiva de insatisfação resulta de um somatório de ações pouco afirmativas levadas a cabo pelas emissoras públicas. Elas terminaram por estabelecer ao longo da história, uma trajetória inconstante e conturbada para os processos que configuraram seus significados no imaginário de parte significativa da população brasileira. O fato de parcela representativa dos participantes da investigação estar insatisfeita com essas emissoras não pode ser atribuído ou justificado como algo momentâneo. Está referenciada, em parte, pela interação com a programação de forma esporádica e a imagem que se formou no seu imaginário a partir da opinião negativa disseminada socialmente. $\mathrm{O}$ problema é bem mais profundo pois, apesar de parte dos pesquisados se apresentarem como consumidores eventuais de meios públicos, possuem uma visão contrária a eles e o pior, com pouca disposição de alterar a sua postura crítica.

Esse distanciamento existente entre cidadãos e meios públicos pode ser percebido nos dados de audiência do setor. No caso da EBC, os melhores índices de audiência em 
sua rede de televisão não alcançam sequer, no Rio de Janeiro e em São Paulo, as duas maiores praças do Brasil, a casa de 1\%, em média, nos seus melhores momentos ${ }^{13}$. A situação apresentada nesses dois centros urbanos é representativa da precária penetração dos meios públicos. $\mathrm{O}$ contexto tende a piorar ainda mais se considerarmos, também, que em muitas outras cidades brasileiras uma expressiva quantidade de emissoras de rádio e televisão públicas nem sequer aparecem listadas em pesquisas de registro de audiência. Circunstâncias que o mercado representa pelo "traço"

Essa situação, que termina por demonstrar a séria crise de representatividade vivenciada pelos meios públicos, antecipa os desafios que estes veículos terão de enfrentar já, para se tornarem uma opção viável do "cardápio" midiático para os distintos segmentos da população, notadamente os mais jovens. Dessa maneira, o setor parece estar em um "beco sem saída”,

13 Dado constante no Plano de Trabalho da EBC para 2013.

14. Termo utilizado para expressar níveis de audiência inexpressivos ou próximos do zero. já que parcelas representativas da população não os consomem e outras chegam a expressar, inclusive, a sua prévia rejeição em assisti-los, mesmo sem conhecer suas programações mais recentes.

“...se é pública, não me importa, pois eu não vou ver mesmo“

“...eu não conheço muito bem essa área, mas se for público, com certeza é chato"

Nesse contexto, os dados colhidos e analisados até o momento nos indicam que seria altamente recomendável que dirigentes e gestores de meios públicos, inicialmente, tomassem consciência da complexidade do quadro atual que define a relação entre meios e audiências e pensassem múltiplas estratégias de aproximação com seus públicos, visando conquistar maior credibilidade e aumentar os níveis de aceitação da população. Faz-se necessário enfrentar a situação que denominamos de passivo simbólico não somente com declarações de intenção em se vincular aos princípios universais da radiodifusão pública. Trata-se de estabelecer, no âmbito dos meios, análises e avaliações do que fazem e de como fazem, estabelecendo novas posturas em suas programações e apresentando um perfil de produção que se aproprie de elementos do cotidiano de seu público e, com isso, crie maior identidade e aproximação com o cidadão.

Dessa forma, deverá ser potencializada a elaboração de novas imagens que poderão propiciar um processo de ressignificação dos meios públicos, recolocando-os de outras maneiras no imaginário coletivo. $\mathrm{O}$ vínculo social - entre ouvinte/espectador e meios - envolve inserir-se no modo de vida da sociedade, compartilhar patrimônios comuns como a língua, a música, o trabalho, os esportes, as festas, enfim, o imaginário representa a forma como vivemos. Significa transformar o meio em um espaço onde as pessoas se reconheçam como pertencentes e participantes de um determinado contexto. Seria um lugar de identidade cultural, de integração social com uma visão plural sobre o mundo. Implicaria em adotar uma atitude dinâmica, que 
consiste em prever, em compreender e em promover o que quer ser. $\mathrm{O}$ que não pode ser feito somente por meio de um discurso construído a partir de si mesmo, ensimesmado, mas, sobretudo, em profunda sintonia positiva com a audiência, vista não como um monólito, mas essencialmente complexa, multifacetada, desigual e plural. A partir da lógica de identificação, é possível que os meios públicos encontrem seu lugar no cotidiano, colaborando para o reconhecimento e identificação entre pessoas que habitam o mesmo local, que vivem e partilham um modo de vida em comum, interesses, gostos enfim a sua cultura.

\section{Bibliografia}

Baert, P. (2001). La teoría social en el siglo $X X$. Madrid: Alianza Editorial.

Bendix, R. (1986). Max Weber: Um perfil intelectual. Brasília: EDUnB.

Bianco, N. R. D., Esch, C. E., \& Moreira, S. (2012). Radiodifusão pública: um desafio conceitual na América Latina. Estudos em Comunicação, 12, 155-181.

Buarque de Holanda, S. (1995). Raízes do Brasil. São Paulo: Companhia das Letras.

Blumer, H. (1981). El Interaccionismo Simbólico: Perspectiva y método. Barcelona: Editorial Hora.

Mauss, M. (1969). Oeuvres, t. 3. Paris: Ed. de Minuit.
Mead, G.H. (1982). Espíritu, Persona y Sociedad. Barcelona: Paidós.

Perrota, R. (1988). Interazionismo Simbolico. Concetti sensibilizzanti e ricerca empirica. Catania: C.U.E.C.M.

Ritzer, G. (2001). Teoría sociológica moderna. Madrid: McGraw Hill.

Saperas, E. (1998). Manual básico de la teoría de la comunicación. Barcelona, CIMS.

UNESCO. (2001). Public broadcasting: Why? How? Consultado em 20 de fevereiro de 2010. Disponível em http://unesdoc.unesco.org/images/0012/001240/124058Eo.pdf . 